\title{
Quantitative quality assessment of the greenhouse gas inventory for agriculture in Europe
}

\author{
Adrian Leip
}

Received: 5 January 2009 / Accepted: 15 June 2010 / Published online: 17 July 2010

(C) The Author(s) 2010. This article is published with open access at Springerlink.com

\begin{abstract}
The greenhouse gas inventory of the European Communities and its estimation of the uncertainty is built from 15 individual and independent greenhouse gas inventories. This presents a particular challenge and is possible only if homogeneous information is available for all member states and if a proper evaluation of correlation between member states is performed. To this end, we present a methodology that estimates a quantitative measure for the aggregated Tier-level as well as the uncertainty for the main categories in the agriculture sector. In contrast to the approach suggested in the IPCC guidelines, which uses uncertainty estimates for activity data and emissions factors for each source category, the method presented uses quantitative information from individual parameters used in the inventory calculations, in combination with a well defined procedure to aggregate the information. Not surprisingly, $\mathrm{N}_{2} \mathrm{O}$ emissions from agricultural soils are found to dominate the uncertainty. The results demonstrate the importance of correlation, if uncertainties are combined for the whole of Europe. The biggest challenge seems to be to conceptually harmonize the uncertainty estimates for the activity data (which tend to be underestimated) and emission factors (which tend to be overestimated).
\end{abstract}

\section{Introduction}

The use of a robust methodology to estimate the uncertainty in national greenhouse gas $(\mathrm{GHG})$ inventories is becoming increasingly important as the role of the

\footnotetext{
A. Leip

European Commission Joint Research Centre, Institute for Environment and Sustainability, Ispra, Italy

A. Leip $(\bowtie)$

John Research Center, Climate Change Unit T.P. 290, Via E. Fermi, 21027, Ispra, VA, Italy

e-mail: adrian.leip@jrc.ec.europa.eu
} 
uncertainty estimates increases. In the past, the main purpose of uncertainty assessment (UA) was to prioritize future investments for the improvement of the national GHG inventory. Thus it was used to rank the source categories accordingly to obtain better data. Furthermore there is particular academic interest in comparing GHG inventory uncertainties across countries (e.g., Keizer et al. 2007; Monni et al. 2004; Rypdal and Winiwarter 2001), or the results of different methodologies used in the UA (e.g., Olsthoorn and Pielaat 2003; Ramiréz et al. 2006; Winiwarter 2007). It is now recognized that uncertainty estimates will be used to prove the achievement of GHG reduction commitments (Jonas et al. 2007; Monni et al. 2007; Nahorski et al. 2007) or to play a critical role in deciding on reduction projects (e.g., Grassi et al. 2008). Yet, while the quality of the GHG inventories has significantly improved in the last few years and is now generally accepted to be of comparable standard and quality (Leip et al. 2005), the estimates of the uncertainty are far from being comparable and are spread over a large quality range.

While there are several comparative studies on UA in GHG inventories, they are mainly in the framework of an improvement of national approach for UA (see, e.g., Winiwarter (2007) for Austria, Monni et al. (2007) for Finland, Ramiréz et al. (2006) for the Netherlands; Rypdal and Flugsrud (2001) for Norway, Passant (2003) for the United Kingdom). In this paper we present a compilation of uncertainty estimates of member states of the European Union (EU) for the agriculture sector. The European Commission (EC) is the only regional economically integrated organization that has joined the United Nations Framework Convention on Climate Change (UNFCCC) as a party and has thus the same reporting obligations. However, while data for GHG emissions and estimates for the relative uncertainty of activity data and emission factors were taken from the national GHG inventories of the respective member states, a common approach was applied to calculate sectoral and sub-sectoral uncertainty of the emissions. Additionally, we calculated the aggregated uncertainty for the 15 member states of the EU (EU15) which are part of the 'European bubble' (see EEA 2008, 2009). For the EC inventory, uncorrelated emission estimates of the individual countries reduce the level of uncertainty. It is thus important to make assumptions on the level of correlation between member states' emission estimates. We developed an approach that bases the degree of correlation between member states on the Tier level of the national emission inventories, being a further development of the approach already used in earlier EC GHG inventories (see EEA 2007). The term "Tier level" is used in analogy to the IPCC (2000) definition to describe the methodology used. The idea is that the higher the Tier level of the emission estimates, the higher the influence of national information on the emission calculations, and the smaller the degree of correlation among member states. Thus a correlationmatrix is obtained which is used for both an extended Tier 1 for uncertainty (simple error propagation with consideration of correlations) and a Tier 2 (Monte Carlo).

In the following I develop the methodology and show the results for the most recent EC inventory of the year 2008. I then identify necessary improvements to the UA and discuss some critical aspects such as likely over- or underestimation of uncertainties in inventory-input data and possible ways to achieve UAs of comparable content and quality for EU member states. 


\section{Method}

The uncertainty estimates of member states are carried out by Tier 1 or Tier 2 methods following the IPCC guidance (IPCC 2000). As a further development of the approach used in the EC greenhouse gas inventory (EEA 2007), the method used for the UA of the agriculture sector of the combined EC inventory presented here involves several additions to the approaches described in the IPCC guidelines (IPCC 2000, 2006). This includes (1) a quantitative assessment of the Tier level of the emission estimate based on the individual factors and parameters used for all members states and the EC; (2) consistent aggregation of the available uncertainty information to the level of the categories including gap filling where necessary. This is done using both Tier 1 and Tier 2 methodology for both level and trend uncertainty; (3) aggregation of categorical uncertainty estimates to the EU level using quantitative information on the level of independence. As a proxy for the level of independence, the Tier level is used and is defined as follows: Tier 1 if only default IPCC data are used in the estimation equation and Tier 2 if the emissions estimate is based on country-specific data. Through the aggregation of emission data by categories and countries, intermediate values between Tier 1 and Tier 2 become possible.

\subsection{Assessing the Tier level}

The IPCC methodology estimates emissions $E_{s}$ from a certain source category $s$ as:

$$
E_{s}=I E F_{s} \cdot A D_{s}
$$

where $A D_{s}$ is the activity data for the source category $s$ and $I E F_{s}$ is the implied emission factor for this category. There are three levels for estimating the emissions, called Tier 1, Tier 2, and Tier 3, moving from the use of default values through the inclusion of national information to the application of modeling tools. In order to define an EU-wide Tier level per source category and sector, two criteria must be met:

1. For each source category and member state a Tier level must be assigned.

2. To assess the quality of aggregated emissions derived at different Tier level, the Tier levels must be measured on an interval scale, allowing 'intermediate' Tier levels.

To do this, I developed standard procedures for each source category, based on the following principles:

1. The flow of nutrients in agriculture implies that the emission in one category can serve as an activity level in another. Therefore, the Tier level, for example, of the estimate for nitrogen excretion influences the Tier level for nitrous oxide $\left(\mathrm{N}_{2} \mathrm{O}\right)$ emissions from manure management, and also $\mathrm{N}_{2} \mathrm{O}$ emissions from manure application to soils, indirect $\mathrm{N}_{2} \mathrm{O}$ emissions from volatilization of $\mathrm{NH}_{3}+\mathrm{NO}_{\mathrm{x}}$, and $\mathrm{N}_{2} \mathrm{O}$ emissions from nitrogen deposited by grazing animals. 
2. A Tier level is assessed for each parameter by comparing the IPCC default value with the value used by the countries. If the default IPCC value is used, the Tier level is set to 1 and otherwise the Tier level is set to 2. Caution is taken for country-specific data that are identical to the default values. This has been checked "manually."

3. With a few exceptions, a country-specific estimation of the activity data is considered as "standard" for countries in Europe. Only for source categories where particular efforts are needed for a good estimate of the activity is the Tier level of the activity data considered, such as the area of cultivated histosols or the fraction of manure deposited by grazing animals.

For the sake of consistency with the IPCC usage, we evaluate Tier levels in the range $[1,2]$, not considering emission estimates of higher Tier as Tier 2, which, however, have, to date, been very rare in the GHG inventories of European countries.

Tier levels are aggregated applying different aggregation rules:

a. The MEDIAN-rule is applied if the Tier level $T$ of a product of different parameters $P_{i}$ is to be evaluated $\left(T_{\prod_{i} P i}\right)$. The aggregation of the Tier level of these parameters to estimate the Tier level of the emission factor should follow the following principles. (1) If parameters at very different Tier levels are multiplied, the higher level should get more weight; (2) if parameters with different uncertainty are multiplied, it should be good practice to estimate the parameter which is associated with the higher uncertainty at a higher Tier level. Thus, the aggregation rule should reward the fact that efforts have been made to improve uncertain parameters. Where a comprehensive set of relative uncertainty estimates for the individual parameters is lacking, the following equation with an arbitrary weighting factors $w_{\mathrm{p}, \mathrm{j}}$ has been introduced, based on expert judgment:

$$
T_{\prod_{i} P_{i}}=3-\prod_{i}\left[\left(3-T_{P} i\right)^{\frac{w_{p, i}}{\sum_{j}\left\{w_{p, j}\right\}}}\right]
$$

with $i$ and $j$ indicating the individual parameters to be multiplied. The term $\left(3-T_{P i}\right)$ assures that a higher weight is given to the parameter estimated with the higher Tier. For example, this formula is used to estimate the uncertainty of the emission factor for $\mathrm{CH}_{4}$ emissions from manure management, which is calculated as the product of volatile solid excretion (VS), maximum $\mathrm{CH}_{4}$ producing capacity $\left(\mathrm{B}_{0}\right)$, and $\mathrm{CH}_{4}$ conversion factor $(\mathrm{MCF})$. The following weights were used: VS: $0.75, \mathrm{~B}_{0}: 0.125, \mathrm{MCF}: 0.125$. The higher weight for VS is based on the observation that variations of $\mathrm{B}_{0}$ and $\mathrm{MCF}$ are usually small and thus do not greatly contribute to uncertainty of the emission factor. A simplified rule has been applied to estimate the Tier level of $\mathrm{CH}_{4}$ emissions from enteric fermentation, which in many cases is based on, or validated with, direct measurements.

b. The MEAN-rule if an emission estimate is calculated as the sum of two or more sub-categories. In this case, the Tier levels of the individual estimates are aggregated using an emission-weighted average. For example, the Tier level of indirect $\mathrm{N}_{2} \mathrm{O}$ emissions from agriculture $T_{4 \mathrm{D} 3}$ is calculated from the Tier levels 
determined for indirect emissions through volatilization of reactive nitrogen gases $T_{4 \mathrm{D} 3 \mathrm{a}}$ and leaching/run-off of nitrate $T_{4 \mathrm{Db}}$ according to:

$$
T_{\sum_{i} \mathrm{E}_{\mathrm{i}}}=\frac{\sum_{i} T_{\mathrm{i}} \cdot E_{\mathrm{i}}}{\sum_{i} E_{\mathrm{i}}}
$$

\subsection{Assessing the uncertainty at member state level}

The IPCC guidelines (IPCC 2000, 2006) describe two approaches for combining uncertainty in the GHG inventory models. The first approach uses the error propagation method. This method works fine as long as the probability density function (PDF) of the mean is normal and the relative standard deviation $\sigma_{\mathrm{r}}$ is not larger than 0.3. For larger relative standard deviations or skewed distributions IPCC (2006) also gives guidance on how a good estimate for combined uncertainty can nevertheless be achieved. I applied a Tier 1 (uncertainty propagation) and a Tier 2 (Monte Carlo) model to estimate combined uncertainty at member state and EC levels, where this was not yet reported at the required level of aggregation by the member state. For both approaches I considered potential dependencies, expanding the Tier 1 method for additive terms with the following equation:

$$
\begin{gathered}
\sigma_{X \pm Y}^{2}=\sigma_{X}^{2}+\sigma_{Y}^{2} \pm 2 \cdot C O V_{X, Y} \\
\operatorname{COV}_{\mathrm{X}, \mathrm{Y}}=\rho_{X, Y} \cdot \sigma_{X} \cdot \sigma_{\mathrm{Y}}
\end{gathered}
$$

if $\sigma^{2} x$ is the variance of the parameter $\mathrm{X}, \mathrm{COV}_{\mathrm{X}, \mathrm{Y}}$ is the covariance between the parameters $X$ and $Y, \rho_{X, Y}$ is the coefficient of correlation. Both approaches were realized in Spreadsheet models using Visual Basic for Excel® functions. The information on the uncertainty estimates for agricultural sources differs significantly across the 15 member states for which the EC inventory has to be compiled. Some countries report uncertainties at the level of categories; other give detailed information, for example by main animal types or for the different types of nitrogen input contributing to direct $\mathrm{N}_{2} \mathrm{O}$ emissions. For a meaningful comparison and further processing at the EU level, the numbers must be aggregated or gap-filled. As a rule, uncertainties below the subcategory are assumed to be correlated (e.g., when combining dairy and non-dairy cattle or different direct $\mathrm{N}_{2} \mathrm{O}$ sources from agricultural soils), while for the combination of sub-categories (different animal types, direct and indirect $\mathrm{N}_{2} \mathrm{O}$ emissions), the uncertainties were considered to be uncorrelated. The uncertainties of the categories within agriculture are considered to be uncorrelated as well. This is mainly due to the fact that the largest contribution of the uncertainties stems from the emission factors (Leip et al. 2005) so that the uncertainty of the activity data, which might be partly identical across categories, becomes less important. "Gap filling" is done for the combined uncertainty $(\mathrm{AD} * \mathrm{EF})$. For the analysis of the trend uncertainty, gap filling for $A D_{s}$ and $E F_{s}$ is also required. Here, AD uncertainties are gap-filled first on the basis of the model $\sum_{i}\left\{E F_{i} \cdot A D_{i}\right\}=I E F \cdot \sum_{i}\left\{A D_{i}\right\}=I E F \cdot A D$, and missing $\mathrm{EF}$ uncertainties are then calculated on the basis of the formula IEF $=\mathrm{E} / \mathrm{AD}$ for both Tier 1 (with $\left.\left(\sigma_{r, I E F} \cdot I E F\right)^{2}=\left(\sigma_{r, E} \cdot E\right)^{2}-\left(\sigma_{r, A D} \cdot A D\right)^{2}\right)$ and Tier 2. Tables 1 and 2 show that there is large variability in uncertainty estimates for both activity 
Table 1 Summary table for the relative uncertainty in percentage terms for activity data (source: national GHG inventories of EU member states for the year 2007, submitted in 2009, and own calculations)

\begin{tabular}{|c|c|c|c|c|c|c|c|}
\hline & $\begin{array}{l}\text { Total } \\
\mathrm{CH}_{4}+\mathrm{N}_{2} \mathrm{O}\end{array}$ & $\begin{array}{l}4 \mathrm{~A} \\
\mathrm{CH}_{4}\end{array}$ & $\begin{array}{l}4 \mathrm{~B} \\
\mathrm{CH}_{4}\end{array}$ & $\begin{array}{l}4 \mathrm{~B} \\
\mathrm{~N}_{2} \mathrm{O}\end{array}$ & $\begin{array}{l}4 \mathrm{C} \\
\mathrm{CH}_{4}\end{array}$ & $\begin{array}{l}4 \mathrm{D} \\
\mathrm{CH}_{4}\end{array}$ & $\begin{array}{l}4 \mathrm{D} \\
\mathrm{N}_{2} \mathrm{O}\end{array}$ \\
\hline Austria & 4 & 10 & 7 & 10 & & & 4 \\
\hline Belgium & 12 & 5 & 10 & 10 & & & 30 \\
\hline Denmark & 5 & 10 & 10 & 10 & & & 7 \\
\hline Finland $^{\mathrm{a}}$ & 12 & & & & & & \\
\hline France & 5 & 5 & 5 & 5 & & & 10 \\
\hline \multicolumn{8}{|l|}{ Germany ${ }^{\mathrm{a}}$} \\
\hline Greece & 15 & 5 & 5 & 50 & 2 & & 22 \\
\hline Ireland & 1 & 1 & 1 & 11 & & & \\
\hline Italy & 9 & 20 & 20 & 20 & 3 & & 14 \\
\hline Luxembourg & 4 & 2 & 2 & & & & 9 \\
\hline Netherlands & 8 & 4 & 9 & 10 & & & 17 \\
\hline Portugal & 12 & 9 & 34 & 39 & 37 & & 30 \\
\hline Spain & 44 & 3 & 3 & 16 & & & 102 \\
\hline Sweden & 9 & 5 & 20 & 20 & & & 16 \\
\hline United Kingdom & 1 & 0 & 0 & 1 & & & 1 \\
\hline
\end{tabular}

$4 A$ enteric fermentation, $4 B$ manure management, $4 C$ rice cultivation, $4 D$ agricultural soils

a Some countries do not report uncertainty estimates for $\mathrm{AD}$, as the uncertainty assessment is done with a dedicated model and the combined uncertainty estimate is reported as EF-uncertainty

data (Table 1) and emission factors as they are reported in the national inventory reports of the member states of the European Union. The variability will be further discussed below.

Table 2 Summary table for the relative uncertainty in percentage terms for the implied emission factors (source: national GHG inventories of EU member states for the year 2007, submitted in 2009 , and own calculations)

\begin{tabular}{lccccccr}
\hline & Total & $4 \mathrm{~A}$ & $4 \mathrm{~B}$ & $4 \mathrm{~B}$ & $4 \mathrm{C}$ & $4 \mathrm{D}$ & $4 \mathrm{D}$ \\
& $\mathrm{CH}_{4}+\mathrm{N}_{2} \mathrm{O}$ & $\mathrm{CH}_{4}$ & $\mathrm{CH}_{4}$ & $\mathrm{~N}_{2} \mathrm{O}$ & $\mathrm{CH}_{4}$ & $\mathrm{CH}_{4}$ & $\mathrm{~N}_{2} \mathrm{O}$ \\
\hline Austria & 41 & 22 & 50 & 100 & & & 101 \\
Belgium & 98 & 40 & 41 & 91 & & & 252 \\
Denmark & 18 & 13 & 100 & 100 & & & 24 \\
Finland & 45 & 32 & 16 & 82 & & & 75 \\
France & 100 & 40 & 50 & 50 & & & 200 \\
Germany & 158 & 6 & 12 & 21 & & 50 & 307 \\
Greece & 63 & 30 & 50 & 112 & 40 & & 95 \\
Ireland & 22 & 11 & 11 & 101 & & & 58 \\
Italy & 36 & 28 & 102 & 102 & 20 & & 67 \\
Luxembourg & 82 & 30 & 145 & & & & 159 \\
Netherlands & 41 & 15 & 70 & 100 & & & 83 \\
Portugal & 76 & 14 & 82 & 107 & 55 & & 227 \\
Spain & 104 & 11 & 11 & 101 & & & 239 \\
Sweden & 41 & 25 & 54 & 54 & & & 71 \\
United Kingdom & 229 & 20 & 30 & 414 & & & 424 \\
\hline
\end{tabular}

$4 A$ enteric fermentation, $4 B$ manure management, $4 C$ rice cultivation, $4 D$ agricultural soils 
The Monte Carlo calculation includes a control on the likely PDF of the mean. If the relative uncertainty exceeds 0.4 then it is assumed that the mean is lognormally distributed and the distribution is transformed with $\mu_{1}=\log _{10}\left\{\mu_{n}\right\}$ and $\sigma_{1}=\log _{10}\left(1+\sigma_{\mathrm{n}} / 100\right)$.

The trend uncertainty is calculated with both standard Tier 1 (IPCC 2006) and Monte Carlo calculation.

\subsection{Assessing the uncertainty at the EU level}

Uncertainties for source categories in the agriculture sector and for the sector as a whole are combined considering an assumed degree of dependence between each pair of countries. The quantitative assessment of the Tier levels outlined in Section 2.1 helps to derive a reasonable estimate for the correlation coefficient $\rho_{\mathrm{XY}}$ between two countries $\mathrm{X}$ and $\mathrm{Y}$. To this end, the Tier levels $T_{\mathrm{X}}$ and $T_{\mathrm{Y}}$ are used in the following equation:

$$
\rho_{X, Y}=\sqrt{\left(2-T_{X}\right) \cdot\left(2-T_{Y}\right)}
$$

Equation 6 leads to the situation of no correlation $\left(\rho_{X, Y}=0\right)$ for two countries with a Tier 2 and full correlation $\left(\rho_{X, Y}=1\right)$ if both countries used a Tier 1 . A correlation coefficient can be calculated for any intermediate situation. This information is further processed within the standard IPCC Tier 1 and Monte Carlo methods for both level and trend uncertainty.

\section{Results}

Table 3 summarizes the Tier levels calculated for EU15 countries for the main source categories in agriculture. Enteric fermentation and manure management emissions are largely based on a characterization of the animal performance. This is conducted for animal types relevant for $\mathrm{CH}_{4}$ emissions from enteric fermentation. For $\mathrm{CH}_{4}$ emissions from manure management other animals are relevant (swine, poultry) with the consequence that the Tier level for $\mathrm{CH}_{4}$ emission estimates from manure management is, with Tier 1.6, somewhat lower than for $\mathrm{CH}_{4}$ emissions estimates for enteric fermentation. Nitrogen excretion data are in many cases based on national studies, which makes the estimate for $\mathrm{N}_{2} \mathrm{O}$ emissions from manure management of a higher Tier (Tier 1.7 for EU15). For $\mathrm{N}_{2} \mathrm{O}$ emissions from agricultural soils, only few countries have developed national emission factors, even though national information for other parameters, particularly volatilization and leaching fractions, make the Tier level higher than 1 . Very different approaches are used to estimate $\mathrm{CH}_{4}$ emissions from agricultural soils; most countries do not report this source category. While two countries estimate $\mathrm{CH}_{4}$ emissions from sewage sludge applied to soils, one country estimates this source category as uptake of $\mathrm{CH}_{4}$ in aerobic soils.

The result of the uncertainty assessment (Tier 1) is shown in Table 4. For the EC uncertainty, five scenarios are calculated to give an idea for the range of possible uncertainty values. The first scenario calculates the uncertainty using the "most probable" correlation level as defined above. However, particularly for $\mathrm{N}_{2} \mathrm{O}$ 
Table 3 Summary table for the tier level assessment for EU15 countries, based on information for national GHG inventories for the year 2007, submitted in 2009

\begin{tabular}{llllllll}
\hline & Total & $4 \mathrm{~A}$ & $4 \mathrm{~B}$ & $4 \mathrm{~B}$ & $4 \mathrm{C}$ & $4 \mathrm{D}$ & $4 \mathrm{D}$ \\
& $\mathrm{CH}_{4}+\mathrm{N}_{2} \mathrm{O}$ & $\mathrm{CH}_{4}$ & $\mathrm{CH}_{4}$ & $\mathrm{~N}_{2} \mathrm{O}$ & $\mathrm{CH}_{4}$ & $\mathrm{CH}_{4}$ & $\mathrm{~N}_{2} \mathrm{O}$ \\
\hline Austria & Tier 1.6 & Tier 1.9 & Tier 1.8 & Tier 1.7 & & Tier 2.0 & Tier 1.3 \\
Belgium & Tier 1.7 & Tier 1.9 & Tier 1.9 & Tier 2.0 & & Tier 2.0 & Tier 1.5 \\
Denmark & Tier 1.7 & Tier 2.0 & Tier 1.9 & Tier 1.9 & & & Tier 1.5 \\
Finland & Tier 1.6 & Tier 1.9 & Tier 1.6 & Tier 1.4 & & & Tier 1.5 \\
France & Tier 1.4 & Tier 2.0 & Tier 1.2 & Tier 1.5 & Tier 1.0 & & Tier 1.1 \\
Germany & Tier 2.0 & Tier 2.0 & Tier 1.9 & Tier 2.0 & & Tier 2.0 & Tier 2.0 \\
Greece & Tier 1.2 & Tier 1.6 & Tier 1.1 & Tier 1.7 & Tier 1.0 & & Tier 1.1 \\
Ireland & Tier 1.7 & Tier 2.0 & Tier 1.6 & Tier 1.7 & & & Tier 1.3 \\
Italy & Tier 1.5 & Tier 1.8 & Tier 1.8 & Tier 1.7 & Tier 2.0 & & Tier 1.3 \\
Luxembourg & Tier 1.5 & Tier 2.0 & Tier 1.8 & & & & Tier 1.2 \\
Netherlands & Tier 1.9 & Tier 1.9 & Tier 2.0 & Tier 1.7 & & & Tier 1.9 \\
Portugal & Tier 1.7 & Tier 2.0 & Tier 1.9 & Tier 1.7 & Tier 1.0 & & Tier 1.4 \\
Spain & Tier 1.8 & Tier 1.9 & Tier 1.8 & Tier 1.7 & & & Tier 1.7 \\
Sweden & Tier 1.8 & Tier 1.9 & Tier 1.9 & Tier 1.7 & & & Tier 1.8 \\
United Kingdom & Tier 1.5 & Tier 1.9 & Tier 1.6 & Tier 1.8 & & & Tier 1.2 \\
EU-15 & Tier 1.6 & Tier 1.9 & Tier 1.6 & Tier 1.7 & Tier 1.6 & Tier 2.0 & Tier 1.4 \\
\hline
\end{tabular}

$4 A$ enteric fermentation, $4 B$ manure management, $4 C$ rice cultivation, $4 D$ agricultural soils

Table 4 Summary table for the uncertainty assessment (relative uncertainties (Tier 1) in percentage of mean emission estimate, based on information for national GHG inventories for the year 2007, submitted in 2009)

\begin{tabular}{lcrrrrrr}
\hline & Total & \multicolumn{1}{c}{$4 \mathrm{~A}$} & \multicolumn{1}{c}{$4 \mathrm{~B}$} & \multicolumn{1}{c}{$4 \mathrm{~B}$} & $4 \mathrm{C}$ & $4 \mathrm{D}$ & \multicolumn{1}{c}{$4 \mathrm{D}$} \\
& $\mathrm{CH}_{4}+\mathrm{N}_{2} \mathrm{O}$ & $\mathrm{CH}_{4}$ & \multicolumn{1}{c}{$\mathrm{CH}_{4}$} & \multicolumn{1}{c}{$\mathrm{N}_{2} \mathrm{O}$} & $\mathrm{CH}_{4}$ & $\mathrm{CH}_{4}$ & $\mathrm{~N}_{2} \mathrm{O}$ \\
\hline Austria & 40.5 & 22.4 & 50.1 & 100.5 & & & 100.6 \\
Belgium & 98.3 & 40.3 & 41.2 & 90.6 & & & 251.8 \\
Denmark & 18.4 & 12.8 & 100.5 & 100.5 & & & 24.1 \\
Finland & 44.8 & 32.1 & 15.9 & 82.0 & & & 74.9 \\
France & 100.2 & 40.3 & 50.2 & 50.2 & & & 200.2 \\
Germany & 158.4 & 5.9 & 11.6 & 20.9 & & 50.0 & 306.6 \\
Greece & 63.2 & 30.4 & 50.2 & 111.8 & 40.0 & & 95.0 \\
Ireland & 21.7 & 11.4 & 11.2 & 100.6 & & & 57.9 \\
Italy & 35.5 & 28.3 & 102.0 & 102.0 & 20.2 & & 66.5 \\
Luxembourg & 82.1 & 30.1 & 144.6 & & & & 158.7 \\
Netherlands & 40.5 & 15.2 & 69.7 & 100.5 & & & 82.8 \\
Portugal & 76.2 & 14.4 & 82.2 & 107.3 & 54.7 & & 227.3 \\
Spain & 103.6 & 11.4 & 11.4 & 101.3 & & & 239.3 \\
Sweden & 40.8 & 25.5 & 53.9 & 53.9 & & & 70.5 \\
United Kingdom & 229.1 & 20.0 & 30.0 & 414.0 & & & 424.0 \\
EU-15* & 67.5 & 11.5 & 25.7 & 61.4 & 19.8 & 50.0 & 156.6 \\
No correlation & 45.4 & 10.5 & 18.0 & 41.6 & 18.7 & 50.0 & 93.1 \\
Full correlation & 102.4 & 22.6 & 40.7 & 101.0 & 27.9 & 50.0 & 209.9 \\
Only 4D uncorr & 46.4 & 22.6 & 40.7 & 101.0 & 27.9 & 50.0 & 93.1 \\
Only 4D corr. & 102.0 & 10.5 & 18.0 & 41.6 & 18.7 & 50.0 & 209.9 \\
\hline
\end{tabular}

$4 A$ enteric fermentation, $4 B$ manure management, $4 C$ rice cultivation, $4 D$ agricultural soils 
emissions from agricultural soils, the dependence on other exogenous factors that are not part of the inventory system might influence the uncertainty distribution, so that the "most probable" level of correlation does not necessarily reflect the reality. Therefore, a second scenario assumes no correlation between the uncertainty estimates of the individual countries, while the third scenario assumes full correlation. Obviously, this scenario leads to the highest overall uncertainty estimates of $102 \%$ for agriculture. Two additional scenarios calculate the bounds for the uncertainty estimate assuming that the member states' estimate for agricultural soils is uncorrelated, but the estimates of all other sub-categories is correlated (lower bound) and finally that only agricultural soil estimates are correlated (upper bound). The table shows that both bounds are shifted only slightly, the lower from $45.4 \%$ to $46.4 \%$ and the upper from $102.4 \%$ to $102.0 \%$. This highlights again the importance of $\mathrm{N}_{2} \mathrm{O}$ emissions from agricultural soils, which is further translated into the overall GHG inventory, as shown in Table 5, giving the uncertainty values as a percentage of the total GHG emissions, where it induces a range of the total uncertainty from $4 \%$ to $9 \%$. If agriculture were not part of the GHG inventory, the uncertainty would be at a level of $1.4 \%$ ! The analysis of the trend analysis yields similar results as calculated in EEA (2009), and shown in Table 6. The trend uncertainty is calculated following the methodology proposed in the IPCC (2000) guidelines. The table shows that agriculture contributes $1.2 \%$ to the total trend uncertainty of the EC GHG inventory of $8.4 \%$ (EEA 2009) and that, again, $\mathrm{N}_{2} \mathrm{O}$ emissions from agricultural soils dominate.

Table 5 Member states' contribution of uncertainty in agriculture to the overall uncertainty estimate emission data from EEA (2009). Relative uncertainty in percentage of total emissions from agriculture, based on information for national GHG inventories for the year 2007, submitted in 2009

\begin{tabular}{|c|c|c|c|c|c|c|c|}
\hline & $\begin{array}{l}\text { Total } \\
\mathrm{CH}_{4}+\mathrm{N}_{2} \mathrm{O}\end{array}$ & $\begin{array}{l}4 \mathrm{~A} \\
\mathrm{CH}_{4}\end{array}$ & $\begin{array}{l}4 \mathrm{~B} \\
\mathrm{CH}_{4}\end{array}$ & $\begin{array}{l}4 \mathrm{~B} \\
\mathrm{~N}_{2} \mathrm{O}\end{array}$ & $\begin{array}{l}4 \mathrm{C} \\
\mathrm{CH}_{4}\end{array}$ & $\begin{array}{l}4 \mathrm{D} \\
\mathrm{CH}_{4}\end{array}$ & $\begin{array}{l}4 \mathrm{D} \\
\mathrm{N}_{2} \mathrm{O}\end{array}$ \\
\hline Austria & 3.7 & 0.8 & 0.5 & 1.0 & & & 3.4 \\
\hline Belgium & 7.2 & 1.1 & 0.5 & 0.5 & & & 7.1 \\
\hline Denmark & 2.8 & 0.5 & 1.6 & 0.9 & & & 2.0 \\
\hline Finland & 3.2 & 0.6 & 0.1 & 0.5 & & & 3.0 \\
\hline France & 18.1 & 2.2 & 1.3 & 0.6 & & & 17.9 \\
\hline Germany & 8.5 & 0.1 & 0.1 & 0.1 & & 0.0 & 8.7 \\
\hline Greece & 5.4 & 0.7 & 0.2 & 0.2 & 0.0 & & 5.4 \\
\hline Ireland & 5.6 & 1.5 & 0.3 & 0.6 & & & 5.3 \\
\hline Italy & 2.4 & 0.6 & 0.6 & 0.7 & 0.1 & & 2.1 \\
\hline Luxembourg & 4.5 & 0.6 & 1.1 & & & & 4.2 \\
\hline Netherlands & 3.6 & 0.5 & 0.9 & 0.4 & & & 3.4 \\
\hline Portugal & 7.1 & 0.5 & 1.2 & 0.8 & 0.3 & & 6.9 \\
\hline Spain & 10.8 & 0.3 & 0.2 & 0.7 & & & 10.7 \\
\hline Sweden & 5.3 & 1.1 & 0.4 & 0.4 & & & 5.1 \\
\hline United Kingdom & 15.6 & 0.5 & 0.1 & 1.1 & & & 15.5 \\
\hline EU-15 & 6.2 & 0.3 & 0.3 & 0.3 & 0.0 & 0.0 & 7.0 \\
\hline EU-15 no corr & 4.2 & 0.3 & 0.2 & 0.2 & 0.0 & 0.0 & 4.2 \\
\hline EU-15 full corr & 9.4 & 0.7 & 0.5 & 0.6 & 0.0 & 0.0 & 9.4 \\
\hline
\end{tabular}

$4 A$ enteric fermentation, $4 B$ manure management, $4 C$ rice cultivation, $4 D$ agricultural soils, $4 D 1$ direct $\mathrm{N}_{2} \mathrm{O}$ emissions, $4 D 2 \mathrm{~N}_{2} \mathrm{O}$ emissions from grazing animals, $4 D 3$ indirect $\mathrm{N}_{2} \mathrm{O}$ emissions 
Table 6 Trend uncertainty in percent-points of the overall EC GHG inventory, based on information for national GHG inventories for the year 2007, submitted in 2009

\begin{tabular}{|c|c|c|c|c|c|c|c|}
\hline & $\begin{array}{l}\text { Total } \\
\mathrm{CH}_{4}+\mathrm{N}_{2} \mathrm{O}\end{array}$ & $\begin{array}{l}4 \mathrm{~A} \\
\mathrm{CH}_{4}\end{array}$ & $\begin{array}{l}4 \mathrm{~B} \\
\mathrm{CH}_{4}\end{array}$ & $\begin{array}{l}4 \mathrm{~B} \\
\mathrm{~N}_{2} \mathrm{O}\end{array}$ & $\begin{array}{l}4 \mathrm{C} \\
\mathrm{CH}_{4} \\
\end{array}$ & $\begin{array}{l}4 \mathrm{D} \\
\mathrm{CH}_{4}\end{array}$ & $\begin{array}{l}4 \mathrm{D} \\
\mathrm{N}_{2} \mathrm{O}\end{array}$ \\
\hline Austria & 0.02 & 0.01 & 0.00 & 0.00 & & & 0.01 \\
\hline Belgium & 0.07 & 0.01 & 0.01 & 0.00 & & & 0.07 \\
\hline Denmark & 0.03 & 0.01 & 0.01 & 0.00 & & & 0.02 \\
\hline Finland & 0.02 & 0.00 & 0.00 & 0.00 & & & 0.02 \\
\hline France & 0.49 & 0.06 & 0.02 & 0.02 & & & 0.48 \\
\hline Germany & 0.34 & 0.01 & 0.00 & 0.00 & & & 0.34 \\
\hline Greece & 0.08 & 0.01 & 0.00 & 0.01 & 0.00 & & 0.08 \\
\hline Ireland & 0.01 & 0.00 & 0.00 & 0.00 & & 0.00 & 0.01 \\
\hline Italy & 0.13 & 0.08 & 0.02 & 0.03 & 0.00 & & 0.09 \\
\hline Luxembourg & 0.00 & 0.00 & 0.00 & & & & 0.00 \\
\hline Netherlands & 0.08 & 0.01 & 0.01 & 0.00 & & & 0.08 \\
\hline Portugal & 0.06 & 0.01 & 0.01 & 0.01 & 0.01 & & 0.06 \\
\hline Spain & 0.71 & 0.02 & 0.01 & 0.02 & & & 0.71 \\
\hline Sweden & 0.03 & 0.01 & 0.00 & 0.00 & & & 0.03 \\
\hline United Kingdom & 0.78 & 0.01 & 0.01 & 0.05 & & & 0.78 \\
\hline EU-15 & 1.2 & 0.1 & 0.0 & 0.1 & 0.0 & 0.0 & 1.2 \\
\hline
\end{tabular}

$4 A$ enteric fermentation, $4 B$ manure management, $4 C$ rice cultivation, $4 D$ agricultural soils

\section{Discussion}

Generally, uncertainties in input data need to be derived from indirect sources or from expert judgments. A comparison of the uncertainty estimates of five inventories in the late 1990s (Rypdal and Winiwarter 2001), showed that the main reason for the difference in estimated uncertainty is the differences in the assessment of $\mathrm{N}_{2} \mathrm{O}$ emissions from agricultural soils. We find striking differences in the uncertainty estimates from different countries, in that in many cases higher uncertainties are reported in countries where large efforts were put into the agricultural GHG inventory. Monni et al. (2004) also stress that differences in reported uncertainties are in large part due to different ways of assessing the uncertainty. Rypdal and Flugsrud (2001) describe two ways to handle correlations. One way is to aggregate the input data set in such a way that the dependencies are eliminated and the other solution is to explicitly model the dependencies in the analysis, if this is allowed by the method used. The IPCC Good Practice Guidance (IPCC 2000) notes that correlations, even if they exist, may not be important for the uncertainty assessment of a GHG inventory if the dependency is not sufficiently strong or the inventory is not sensitive to the dependent inputs. Nevertheless, consideration of correlation between countries is important as this lead to a significant reduction of the uncertainty of emission estimates when combined to the EC level. If countries are relying on default $E F_{s}$, the distribution of the true mean value is likely to be the same, unless national circumstances differ in important driving factors for that source category in which case the true mean would have to be sampled from a different probability distribution. New scientific evidence would lead to an upward or downward correction of the emission strength for all countries using this default emission factor. Therefore, the EC-IR (EEA 2009) assumed that the uncertainty of those countries are correlated which are using a Tier 1 methodology, while the countries using Tier 2 methodology were assumed to be 
uncorrelated. This approach is not satisfactory, as it neglects that most calculations are conducted with several parameters so that the degree of "independence" varies with the amount of effort that has been put into the development of country-specific parameters. Hence, the analysis presented in this paper extends the approach of the EC-IR by quantifying a degree of independence between categories and countries on the basis of the Tier level as defined in the IPCC guidelines, but applying this definition not only to activity data or emission factors, but to each individual datum used in the calculation of the emissions.

The quantification of the degree of independence and its use for the combination of uncertainties was the main aim in developing the approach for aggregating the Tier levels; it has therefore been tailored to be an indicator of the influence of country-specific information on the emission estimates. It is thus a measure for the methodology used and does not automatically imply that a high "degree of independence" goes hand in hand with a high "quality level," as no evaluation of the data or the approach used has been performed. Nevertheless, an emission estimate that was derived with a higher Tier level should also be more accurate and less uncertain, and thus of a better quality, given the fact that all national GHG inventories considered here were subject to strict review by the UNFCCC Secretariat.

However, not all correlations between source categories could yet be considered. Important dependencies between the estimated amount of manure produced in a country and emissions of $\mathrm{N}_{2} \mathrm{O}$ from various source categories "down the pipe" such as $\mathrm{N}_{2} \mathrm{O}$ emissions from manure management, and direct and indirect $\mathrm{N}_{2} \mathrm{O}$ following application of manure to soils, could not be quantified, as uncertainty values of $\mathrm{N}$ excretion data are not reported by the countries. The large range of uncertainties reported for the $\mathrm{N}$-input to agricultural soils (between $1 \%$ and $75 \%$ ) suggests that these dependencies are inherently considered by some countries, but neglected by others. A common approach to handling these dependencies is important to increase the comparability of the uncertainty estimates across countries.

The comparison between the two approaches-error propagation with consideration of correlation versus the Monte Carlo analysis - confirms that both approaches yield very similar results (e.g., Monni et al. 2004; Ramiréz et al. 2006; Winiwarter 2007). Monte Carlo results are in most cases within 10\% of the estimates obtained with the Tier 1 approach. Moreover, the aggregation of uncertainty estimates from country- to Europe-level yields only slight differences between the approaches, of a few percentage points. Differences, however, appear for emission estimates with high uncertainties such as $\mathrm{N}_{2} \mathrm{O}$ emissions from agricultural soils (data now shown).

\subsection{Activity data uncertainty is likely to be under-estimated}

The final goal of the assessment was to obtain a realistic uncertainty estimate for the area covered by all 15 countries considered. However, this not only depends on an appropriate approach to combining the uncertainty estimates from the individual countries; it should also be checked whether these estimates themselves are comparable and/or realistic. For example, several countries use the same uncertainty value for the $\mathrm{AD}$ of $\mathrm{CH}_{4}$ emissions from enteric fermentation and $\mathrm{CH}_{4}$ and/or $\mathrm{N}_{2} \mathrm{O}$ emissions from manure management (see Table 1). Taking the AD uncertainty in category $4 \mathrm{~A}$ for describing the accuracy of the livestock population, the $\mathrm{AD}$ 
uncertainty for category 4B(a) should, strictly speaking, include the uncertainties for the allocation of manure to climate regions and manure management systems. The AD uncertainty for $\mathrm{N}_{2} \mathrm{O}$ emissions should include both the uncertainty for the allocation of manure to the manure management systems and the nitrogen excretion factors. For the latter, IPCC (2000) recommends an uncertainty range of $\pm 50 \%$ if using default values, down to $\pm 25 \%$ if country-specific information is used. In view of this recommendation, most countries appear to underestimate the uncertainty surrounding their estimate for the AD in category $4 \mathrm{~B}(\mathrm{~b})$.

The allocation of manure to the different manure management systems is a parameter which is highly controlled by the structure of the agricultural sector in a country (for example, increasing the average size and specialization of agricultural holdings in a country generally also implies that a higher percentage of the manure is managed in liquid systems) but also by environmental (e. g., $\mathrm{NH}_{3}$ ceilings) and animal welfare policies (Leip 2005a; Petersen et al. 2007). This also makes this parameter highly dynamic for the time period since 1990, which can be observed for those countries that have estimated an increase/decrease in the importance of manure management systems by up to a factor of more than two (EEA 2009). However, even in these countries, statistics on the management systems for manure rarely exist and, having not usually been surveyed for the whole time period since 1990, are to a large degree based on expert judgment. Hence, in many cases the error made will vary significantly with time and it is unlikely that the distribution of manure management systems in a country is known with a higher accuracy than $20 \%$. In Sweden, statistics on animal waste management systems have been available every 2 years since 1997 , yet this country is among those with the highest estimate for the uncertainty for the $\mathrm{AD}$ in category $4 \mathrm{~B}(\mathrm{a})$. We therefore consider it very likely that most countries are underestimating this uncertainty.

4.2 Correct allocation of sources of error to activity data and emission factors is important for estimating trend uncertainty

One explanation could be that these uncertainties are calculated into the estimate for the EF uncertainty (see Table 2). For category 4B(a), we find values ranging from $11 \%$ to over $100 \%$. This should cover the uncertainties associated with the estimates of the content of volatile solid excretion, the maximum $\mathrm{CH}_{4}$ producing capacity, and the methane conversion factor. The allocation of an uncertainty estimate to AD or EF remains important as long as standard rules are applied to evaluate correlation in time and therefore the trend uncertainty.

As a default, IPCC considers $A D_{s}$ as uncorrelated in time and $E F_{s}$ as correlated. The idea is straightforward: activity data are usually based on statistical surveys, and the error made in 1 year is independent of the error made in another year; thus no correlation in time is assumed. The uncertainty around emission factors is in most cases determined by scientific knowledge gaps (i.e., leading to a bias in unknown direction and quantity) or by high variability encountered in field measurements, as is the case, for example, for the $\mathrm{N}_{2} \mathrm{O}$ emission factor for agricultural soils. However, the shift of the uncertainty surrounding, for example, the manure management system allocation (when this is not correlated in time) into the EF uncertainty estimates would lead to a significant underestimation of the trend uncertainty. A similar discussion also applies to the AD uncertainty estimates for $\mathrm{N}_{2} \mathrm{O}$ emissions from 
agricultural soils, where very large differences are observed (ranging from $1 \%$ to $102 \%$, see Table 1 ).

\subsection{Uncertainty of the emission factor for $\mathrm{N}_{2} \mathrm{O}$ emissions from agricultural soils} could be overestimated

One of the most important elements in today's uncertainty assessment of GHG inventories is the uncertainty of the emission factors used to estimate $\mathrm{N}_{2} \mathrm{O}$ emissions from agricultural soils. The uncertainty range for direct $\mathrm{N}_{2} \mathrm{O}$ emissions proposed in the IPCC (2000) is based on an assessment of Bouwman (1994) who analyzed a compilation of flux measurements and concluded that the best estimate ranges from $0.25 \%$ to $2.25 \%$ covering more than $90 \%$ of the published emission values (IPCC 1997). Even though the central value of the emission factor remained unchanged in the Good Practice Guidance, the uncertainty range was updated, accounting for the fact that measured $\mathrm{N}_{2} \mathrm{O}$ emission factors have a skewed distribution and that the best estimate for the confidence limit ranges is set to one-fifth to five times the default emission factor of $1.25 \%$ (IPCC 2000). In the revised IPCC guidelines (2006), the $\mathrm{N}_{2} \mathrm{O}$ emission factor for direct emissions was changed from $1.25 \%$ to $1 \%$ as a result of an analysis of the same, but updated, data by Bouwman et al. (2002) and Stehfest and Bouwman (2006). The confidence interval now ranges from one-third to three times the default emission factor. The reason for this high uncertainty for this source category is "natural variability, partitioning fractions, activity data, lack of coverage of measurements, spatial aggregation, and lack of information on specific on-farm practices. Additional uncertainty will be introduced in an inventory when emission measurements that are not representative of all conditions in a country are used" (IPCC 2006).

Natural variability of $\mathrm{N}_{2} \mathrm{O}$ emissions is huge, both in time and space, and across scales from the micro-scale to the plot and regional scale. This means that good predictions of $\mathrm{N}_{2} \mathrm{O}$ emissions are impossible unless the major factors influencing the fraction of the $\mathrm{N}$-input which is transformed and emitted as $\mathrm{N}_{2} \mathrm{O}$ are known and an appropriate model is available. For national GHG inventories, this natural variability is important only as far as the assembly of conditions encountered in the country does not compensate for it.

Several studies have shown that the IPCC emission factor seems to be fairly accurate if larger regions (countries or group of countries) are looked at. See, for example, Li et al. (2001), Leip et al. (2008), Del Grosso et al. (2005) and ButterbachBahl and Werner (2005) for model simulations in China, Europe, the United States, and Germany, respectively. This was also confirmed by the detailed analysis in Finland by Monni et al. (2007) who found that the yearly variation of $\mathrm{N}_{2} \mathrm{O}$ emissions in Finland was relatively small $(-104$ to $+171 \%)$ and suggested that climate-specific models should be developed that take soil properties into account (Freibauer 2003; Leip 2005b).

The analysis shows that $\mathrm{N}_{2} \mathrm{O}$ emissions from agricultural soils are not only dominating the overall uncertainty of GHG emissions from agriculture, and in many cases also the overall uncertainty of GHG inventories, but they are also dominating the importance of correlation. This implies that particular attention has to be given to the construction of the GHG inventory for this source category with respect to correlations. 
4.4 Improving methods to estimate emission to higher tiers could result in higher trend uncertainty

As discussed above, the concept of activity data and emissions factors as used in the IPCC guidelines gives room for interpretations, with consequences for the uncertainty assessment, particularly the trend assessment. This leads to a conceptual question/methodological problem: if a country goes from Tier 1-based approaches for quantifying emission factors to Tier 2 or even Tier 3-based approaches (i.e., calculated with process-based models); the assumption that these estimates are correlated in time will no longer hold. Thus, if the uncertainty of the emission factor (in one individual year) cannot be reduced under a certain threshold, the improvement of the methodology can lead to an increase in the trend uncertainty. This fact can have two consequences: (1) the country refrains from using higher Tier approaches until the models become sufficiently robust and are thoroughly validated so that the uncertainty of the emission factor falls below the threshold; (2) the models are used to improve the emission factor, but are not part of the inventory system. This could mean that the models run with a sufficiently large sample of weather conditions in order to derive one or more (regional) emission factors that are assumed to be valid for the whole time period (base year until end of commitment period). Both solutions have advantages. The first solution forces countries to check the models through a strict peer review for their own interest. The second solution would assure that emission trends remain controlled by anthropogenic drivers over a commitment period, thus giving a good ratio of benefit (in terms of incentives to implement mitigation measures) versus quality of the emission estimates.

\subsection{Trend uncertainty is very important}

The most important piece of information for the UA is the trend uncertainty. Therefore, the models should be tailored to suit that purpose (see also Monni et al. 2008). In practice, this means that a separation between AD and EF in the methodology proposed by IPCC $(2000,2006)$ should be replaced by a distinction of parameters which are correlated in time (the error thus being dominated by bias rather than by random error or inter-annual variability, as is the case for most default $E F_{s}$ ) and parameters which are not correlated in time (where random error or inter-annual variability dominate the uncertainty such as for most AD and other parameters derived with an accurate model).

\section{Conclusion}

We present a new methodology that estimates the uncertainty for the categories in the agriculture sector using information on the Tier level. In contrast to the approach suggested in the IPCC guidelines, that uses uncertainty estimates for activity data and emission factors for each source category, the method presented uses quantitative information from individual parameters used in the inventory calculations, in combination with a well defined procedure to aggregate, and comes 
up with an-also quantitative-estimate for the Tier and finally the uncertainty. The methodology proposed is based on standard error propagation rules and additional rules for "Tier-level propagation." It considers possible correlation between source categories without the need for Monte Carlo calculations. The method allows a more transparent comparison of the uncertainty of GHG inventories across a group of countries and could thus be used to focus efforts to improve GHG emission estimates at a supra-national level. Not surprisingly, $\mathrm{N}_{2} \mathrm{O}$ emissions from agricultural soils are found to be dominating the uncertainty of not only the agricultural sector, but also the overall GHG inventory for many countries. This suggests that further improvements should focus on programs to reduce the uncertainty of this source category. The analysis shows that differences in the uncertainty data are mainly based on different input data for the calculations, with a likely underestimation of the activity-data uncertainty and an overestimation of the uncertainty of the emission factors. Thus, the biggest challenge seems to be to put uncertainty estimates for AD and EF on a solid and common basis. Efforts should be invested in a harmonization of the concepts underlying the uncertainty assessment. At present, the combination of uncertainties is done with an improved Tier 1 that considers dependencies. The construction of a Monte Carlo model generally adds little accuracy to the uncertainty estimate. The method presented has been applied to the 15 member states that are part of the "European bubble." It could seamlessly be applied to estimate the uncertainty of the anthropogenic emissions at a larger scale, for example Annex I countries or all parties to the UNFCCC.

Open Access This article is distributed under the terms of the Creative Commons Attribution Noncommercial License which permits any noncommercial use, distribution, and reproduction in any medium, provided the original author(s) and source are credited.

\section{References}

Bouwman AF (1994) Method to estimate direct nitrous oxide emissions from agricultural soils, report 773004004. National Institute of Public Health and Environmental Protection, Bilthoven

Bouwman AF, Boumans LJM, Batjes NH (2002) Emissions of $\mathrm{N}_{2} \mathrm{O}$ and $\mathrm{NO}$ from fertilized fields: summary of available measurement data. Glob Biogeochem Cycles 16(4):1058

Butterbach-Bahl K, Werner C (2005) Upscaling of national $\mathrm{N}_{2} \mathrm{O}$ emissions from soils with biogeochemical models-Germany. In: Leip A (ed) $\mathrm{N}_{2} \mathrm{O}$ emissions from agriculture. Report on the expert meeting on "improving the quality for greenhouse gas emission inventories for category 4D," joint research centre, 21-22 October 2004, Ispra. Vol. EUR 21675. Office for Official Publication of the European Communities, Luxembourg, pp 138-134

Del Grosso SJ, Mosier AR, Parton WJ, Ojima DS (2005) DAYCENT model analysis of past and contemporary soil $\mathrm{N}_{2} \mathrm{O}$ and net greenhouse gas flux for major crops in the USA. Soil Tillage Res 83(1):9-24

EEA (2007) Annual European community greenhouse gas inventory 1990-2005 and inventory report 2007. Submission to the UNFCCC Secretariat, European Environment Agency

EEA (2008) Annual European community greenhouse gas inventory 1990-2006 and inventory report 2008. Submission to the UNFCCC Secretariat, European Environment Agency

EEA (2009) Annual European community greenhouse gas inventory 1990-2007 and inventory report 2009. Submission to the UNFCCC Secretariat, European Environment Agency

Freibauer A (2003) Regionalised inventory of biogenic greenhouse gas emissions from European agriculture. Eur J Agron 19:135-160 
Grassi G, Monni S, Federici S, Achard F, Mollicone D (2008) From uncertain data to credible numbers: applying the conservativeness principle to REDD. Environ Res Lett 3:035005

IPCC (1997) Houghton JT, Meira Filho LG, Lim B, Treanton K, Mamaty I, Bonduki Y, Griggs DJ, Callander BA (eds) Revised 1996 IPCC guidelines for national greenhouse gas inventories. IPCC/OECD/IEA, Paris

IPCC (2000) Penman J, Kruger D, Galbally I, Hiraishi T, Nyenzi B, Emmanuel S, Buendia L, Hoppaus R, Martinsen T, Meijer J, Miwa K, Tanabe K (eds) Good practice guidance and uncertainty management in national greenhouse gas inventories. IPCC/OECD/IEA/IGES, Hayama

IPCC (2006) Eggleston HS, Buendia L, Miwa K, Ngara T, Tanabe K (eds) 2006 IPCC guidelines for national greenhouse gas inventories, prepared by the national greenhouse gas inventories programme. IGES, Japan

Jonas M, Gusti M, Jeda W, Nahorski Z, Nilsson S (2007) Comparison of preparatory signal detection techniques for consideration in the (post-)Kyoto policy process. In: Proceedings of the 2 nd international workshop on uncertainty in greenhouse gas inventories, international institute for applied systems analysis, Laxenburg, Austria, pp 107-134

Keizer Cd, Ramírez A, Sluijs JVd (2007) Uncertainty ranges and correlations assumed in tier 2 studies of several European countries. In: Proceedings of the 2nd international workshop on uncertainty in greenhouse gas inventories, international institute for applied systems analysis, Laxenburg, Austria, pp 35-39

Leip A (2005a) Greenhouse gas emissions from agriculture in Europe. In: Kuczynski T, Dämmgen U, Webb J, Myczko A (ed). Emissions from European agriculture. Wageningen Academic Publishers, The Netherlands, pp 35-49

Leip A (2005b) Executive summary and recommendations. In: Leip A (ed) $\mathrm{N}_{2} \mathrm{O}$ emissions from agriculture. Report on the expert meeting on "improving the quality for greenhouse gas emission inventories for category 4D”, joint research centre, 21-22 October 2004, Ispra, Vol. EUR 21675. Office for Official Publication of the European Communities, Luxembourg, pp 155-160

Leip A, Dämmgen U, Kuikman P, van Amstel AR (2005) The quality of European (EU15) greenhouse gas inventories from agriculture. Environ Sci 2(2-3):177-192

Leip A, Marchi G, Koeble R, Kempen M, Britz W, Li C (2008) Linking an economic model for European agriculture with a mechanistic model to estimate nitrogen and carbon losses from arable soils in Europe. Biogeosciences 5(1):73-94. Available at http://www. biogeosciences.net/5/73/2008/bg-5-73-2008.html

Li CS, Zhuang YH, Cao MQ, Crill P, Dai ZH, Frolking S, Moore B, III, Salas W, Song WZ, Wang XK (2001) Comparing a process-based agro-ecosystem model to the IPCC methodology for developing a national inventory of $\mathrm{N}_{2} \mathrm{O}$ emissions from arable lands in China. Nutr Cycl Agroecosyst 60(1-3):159-175

Monni S, Syri S, Savolainen I (2004) Uncertainties in the Finnish greenhouse gas inventory. Environ Sci Policy 7:87-98

Monni S, Syri S, Pipatti R, Savolainen I (2007) Extension of EU emissions trading scheme to other sectors and gases: consequences for uncertainty of total tradable amount. Water Air Soil Pollut Focus 7(4):529-538

Monni S, Grassi G, Leip A (2008) Uncertainty estimation and management in AFOLU sectorbackground paper for the IPCC workshop on IPCC guidance on estimating emissions and removals from land uses, 13-15 May 2008. Helsinki, Finland

Nahorski Z, Horabik J, Jonas M (2007) Compliance and emissions trading under the Kyoto protocol: rules for uncertain inventories. Water Air Soil Pollut Focus 7(4):539-558

Olsthoorn X, Pielaat A (2003) Tier-2 uncertainty analysis of the Dutch greenhouse gas emissions 1999. Institute for Environmental Studies, Amsterdam

Passant NR (2003) Estimation of uncertainties in the national atmospheric emission inventory, AEAT/ENV/R/1039 Issue 1

Petersen SO, Sommer SG, Béline F, Burton C, Dach J, Dourmad JY, Leip A, Misselbrook T, Nicholson F, Poulsen HD, Provolo G, Sørensen P, Vinnerås B, Weiske A, Bernal M-P, Böhm R, Juhász C, Mihelic R (2007) Recycling of livestock manure in a whole-farm perspective. Livest Sci 112:180-191. doi:10.1016/j.livsci.2007.09.001

Ramiréz A, de Keizer C, van der Sluijs JP (2006) Monte Carlo analysis of uncertainties in the Netherlands greenhouse gas emission inventory for 1990-2004, NWS-E-2006-58. Department of Science, Technology and Society, Copernicus Institute for Sustainable Development and Innovation. Utrecht University, Utrecht, Netherlands

Rypdal K, Flugsrud K (2001) Sensitivity analysis as a tool for systematic reductions in greenhouse gas inventory uncertainties. Environ Sci Policy 4(2-3):117-135 
Rypdal K, Winiwarter W (2001) Uncertainties in greenhouse gas emission inventories-evaluation, comparability and implications. Environ Sci Policy 4(2-3):107-116

Stehfest E, Bouwman AF (2006) $\mathrm{N}_{2} \mathrm{O}$ and $\mathrm{NO}$ emissions from agricultural fields and soils under natural vegetation: summarizing available measurement data and modelling of global annual emissions. Nutr Cycl Agroecosyst V74(3):207-228

Winiwarter W (2007) Quantifying uncertainties of the Austrian greenhouse gas inventory. Final report to project no $1 \mathrm{~S} 2.00116 .0 .0$ contracted by Umweltbundesamt, Austrian Research Centres 